\title{
The Virtual Ballet Studio: A Phenomenological Enquiry into the Domestic as Dance-Space During Lockdown
}

Francesca Ferrer-Best, Department of Gender and Cultural Studies, University of Sydney

\section{Abstract}

The paper is based on an autoethnographic study of dancing via Zoom over the Covid19 lockdown in Sydney, Australia. Its theoretical framework takes up Iris Marion Young's critical phenomenology and work on domestic space to think about certain focal points of the experience, such as having a room to move in, the floor, and the screen. The aim is to examine how important dance-space is to the experience of dancing, and what the specifics of our current situation have revealed about dancing that were obscured to a greater extent before: for instance, the embeddedness of a dancer in their context and what this means for thinking about privilege, as well as the curatorial work that goes into making domestic space an aestheticized dance-space. In this way, I propose that Zoom classes, as well as being a distinct new phenomenon, also have much to teach us about 'conventional,' pre-Covid dance practice.

Keywords: Autoethnography, ballet, dance-space, domestic, phenomenological, Zoom

It is common for dancers to travel across the world, leaving family and friends, to dance; they will go wherever the jobs are, or wherever they need to be to train in a specific technique. Until now, I had never questioned the possibility of training somewhere without being there in situ. Training at the Vaganova Ballet Academy, in St. Petersburg, Russia, for example, is not just about the teaching method, it is also the huge, highceilinged, beige studios; another Russian school in Moscow, the Bolshoi, is about the raked (slanted) floors; in London, training at the Royal Ballet School is about being at White Lodge in Richmond Park. Although I am not a professional dancer, travelling can be about what kind of dance I can explore in a place: if I go to New York I can take class at Steps on Broadway, or Alvin Ailey; if I go to Tel Aviv I could try Gaga, Ohad Naharin's movement language. Yet, in lockdown things changed; I took class from three different cities in three different countries, just in the space of a week, and all from my living room. Clearly, space and place are integral to my dance practice at a variety of scalesin different registers and temporalities-from the macro scale of global imagining to 
the sensory immersion in an immediate present. The feel of gripping the wooden ballet barre in my hands, the clean but sweat-tinged smell of dance studios, imagining the possibilities of dancing around the world, and fondly recalling the summers I would dance away from home-all of these bear witness to the significance of places, space and body to dance practice.

Dancers' bodies are anchored to the spaces they work in, are shaped by, and mutate with. Their being-in-the-dance-world is a knot of place-based relations, between studios, mirrors, stages, wings, dressing rooms, and the actors that dwell among them. This worlding of dance is so strong that when you pluck a dancer out of their context, as did New York photographer Dane Shitagi's Ballerina Project, ${ }^{1}$ which photographed them on city streets, the result is striking. The dancer appears as a more-than-human figure inhabiting the everyday. I am thinking of Francesca Hayward, a Principal Dancer at The Royal Ballet, photographed on an empty overground train platform in London. She is en pointe in a low attitude position (supporting leg straight and right leg raised behind her with a bend at the knee). Her arms are in a free kind of first arabesque position (left arm stretched out in front of her eye line, and right arm stretched too, but down and behind). Her weight-bearing toes are placed just behind the platform's yellow line, and she wears a calf-length black coat over a black leotard with bare legs. The image is both uncanny and beautiful, blurring the boundaries of the daily commute, where people shuffle along, heads down, faces reflecting the light of their phones, with the ballet body_taking up space, dancing along the platform's edge.

Today, the dance world itself is balancing on the edge. It has been placed under enormous financial pressure by the pandemic, along with all other arts communities, institutions, and organizations. During Covid-19 the dance world has appeared to move cohesively and quickly in response to its visceral shutting down by putting everything "out there," online. This great opening-up of content and resources has included the streaming of performances by renowned dance companies on platforms like YouTube and Facebook, and the shift of onsite dance classes and training programs online. The latter, the virtual dance class, is the topic of this paper, which asks how it feels to dance at home and in what ways dance-space has folded over into the domestic-which is historically and discursively constructed as feminized space. ${ }^{2}$

To address these questions, during lockdown I conducted an experimental autoethnographic study of my experiences partaking in virtual dance activities. To analyze the data collected, I engage with Maurice Merleau-Ponty's phenomenology and Iris Marion Young's responses to this, as well as her work on the domestic, aiming to provide a critical phenomenology of the domestic as dance-space. I have chosen the combined approaches of critical phenomenology and feminist work on domestic space to engage with how the dancing body operates under these conditions without neglecting the underlying histories and that frame domestic space as feminized, and the real impact this has on an embodied experience of such spaces. 
For Merleau-Ponty, the body has boundaries, but it is also open-ended. ${ }^{3}$ The value in drawing from his position at all, given that I am also using Young, is their combined capacity for exploring a range of phenomenological states; Merleau-Ponty for an expansive insight into the body and space, and Young for her critical and situated understanding of what social constructions, like gender, mean for occupying and moving through those spaces. Before developing my analysis, I situate this research in reference to elements of the existing screendance literature, provide some methodological reflections, and then some contextualization on the positioning of domestic space as proximate with feminized space.

In titling this paper "the virtual ballet studio," I use the term "virtual" as Kiri Miller does, following anthropologist Tom Boellstorff, suggesting that "our 'real' lives have been 'virtual' all along. It is in being virtual that we are human: since it is human 'nature' to experience life through the prism of culture, human being has always been virtual being. ${ }^{5}$ He goes on to clarify that virtuality can exist between the perceived gap of what is, in Aristotelian terms the "actual," and what could be; that is to say, the manifold possibilities of experience. ${ }^{6}$ Miller's case studies of virtual play provide valuable examples of how screen-based activities occupy this in-betweenness in different ways, at times becoming actual, as virtual imagining and exploration transform into embodied practice. ${ }^{7}$

The ways that virtual dance classes have proliferated as a result of Covid represents a genuine break from what existed before, if we are considering classes that operate in a strict pedagogical sense-in a top-down direction from qualified teachers to students. This shift was reflected broadly by a "boom" in working out online. ${ }^{8}$ As Virtuagym (2020), an online fitness technology provider, reports, since the onset of Covid they recorded a " $400 \%$ increase in engagement and a $300 \%$ increase in the use of online workouts." Although innumerable forms of screen-based, digital, and online dance practices predate Covid and have been extensively discussed by scholars, those which I will draw from here, to position this work within the screendance literature, relate specifically to examples that consider the capacity for learning and the transmission of embodied knowledges in online contexts.

Pre-Covid, a burgeoning part of the dance world's online presence was geared towards showcasing classes and choreographic combinations through videos on YouTube and social media platforms, but not strictly as a pedagogical tool. Alexandra Harlig has explored these class videos as screendance texts, developing a system influenced by Ken S. McAllister's work on game play impacts and Miller's virtual play studies, to account for the multivalent ways in which these texts are consumed and responded to. ${ }^{10}$ Harlig uses the concept of "forces" as a framework to engage with this multivalence, and among other types, she discusses "instructional force," which "notes the pedagogical setting of a video as well as the movement, music, and life values transmitted," and "documentary force," accounting "for the informational value of a 
historical record."11 With reference to class videos, Harlig notes the ways that instructional force operates diversely, not just in the sense that by watching the video it is possible to learn the choreography. For instance, class videos can show "how to be an audience member in a Hip-Hop dance environment: throwing shoes, cheering each other on, or hand-propping," and "for budding filmmakers there is information through the site of production about useful shots or successful angles, and how to interact with dancers."12 Harlig's approach promises a breadth of ways in which it is possible to conceive of the impacts of virtual dance classes and could be utilized in further scholarship on the topic-especially through consideration of the confluence of documentary and instructional forces, and what this could mean for thinking about how recorded classes might be used.

In Perpetual Motion: Dance, Digital Cultures, and the Common, Harmony Bench theorizes that "dance circulates as a gift in digital cultures," but not unproblematically, as underlying power structures and appropriative practices become apparent when "dances travel beyond the communities that provide them with context."13 Given the ways that Zoom dance classes proliferated during initial and successive lockdowns globally, it is an interesting notion to consider how these classes may also be conceived as gifts, whose "content ... belongs to a common"14 - that common being communities of dancers in need of them as alternative, virtual modes of practice. But as Bench notes, there is "no single common" with universal accessibility. ${ }^{15}$ While this holds true, Covidera Zoom classes have undoubtedly changed the scope of accessibility for students to partake in learning, and for amateurs and professionals alike to engage with forms of dance that were previously inaccessible to them, often because of geography, but also because of finances and simply not having the spare time. Almost paradoxically, a welcome departure compared with pre-Covid forms of virtual dance is that Zoom classes occur on a schedule, disrupting a sensation of lockdown that speaks to the interminable flexibility of time. Indeed, the gift that is the transmission of dance via digital modalities post-Covid, looks as though it will have a long-term impact on the future of how dance training is provided. For ballet in particular, the spread in popularity of Zoom classes also has the potential to debunk the elite status of the studio. As many dancers will be coming to know, as alien and taxing as it might feel, it is possible to stay in shape and explore new, productive ways of moving without the specialized spaces that dancers are accustomed to.

Perhaps most comparable to what we are seeing in Zoom dance classes in the time of Covid comes from the world of web-native dance-fitness videos. Born of the 1980s trend for dance-fitness from the comfort of your own home, and largely interested in appealing to housewives (who were short on time and/or had young children to care for), aerobic dance-fitness videos have maintained popularity through concurrent decades as a fun and engaging way of exercising at home, with an emphasis on aiding weight loss. ${ }^{16}$ In examples that range from "Jazzercise" tapes from the late 1980s, to 2000s "Pump it up" aerobics DVDs, to the online Zumba classes that are widely available 
on YouTube now, a consistent feature of dance-fitness videos is that the teacher interacts with the participant by talking to them, offering encouragement and reminding them to enjoy themselves despite the fact that the medium is unidirectional.

The similarities of these to Zoom classes are that a) they are home-based activities and b) they offer a notable level engagement from teachers, irrespective of whether that engagement is superficial. There is a consistency of body and space relations between dance-fitness video classes and Zoom dance classes, which feature a pedagogical figure who has a sense of presence emanating from the screen. A further element that makes dance-fitness videos relevant to the broader aims of this paper is that, as I alluded to earlier, dance-fitness videos are represented as a feminine form of exercise, which is something I will take up later in relation to ballet.

As Leslea Haravon Collins suggests "aerobics is one of the few physical activities in which women are encouraged unequivocally to participate, ${ }^{\prime 17}$ and its participants are overwhelmingly women. Although Collins does not consider how the function of aerobics happening at participants' homes contributes towards its feminization, she makes it clear that the dance form itself has essentialising and oppressive notions of what it means to be a woman built into it, i.e. being motivated by the drive to lose weight rather than feel strong. ${ }^{18}$ Considering the home- and screen-based dance practices of dance-fitness/aerobics and Zoom ballet classes together is productive because it emphasizes their shared underlying themes. These themes include the transformation of domestic space into dance-space, and the converged space as being inherently feminized.

\section{Methodological reflections}

In order to explore my own situated insight into what it was like to dance during lockdown, and specifically how domestic space functioned in the experience, I conducted a phenomenologically oriented autoethnography of my own practice of taking virtual ballet classes during the onset of the pandemic. For four months, from April through to July, I used a dual system of fieldnote-taking to document my experience of dancing via Zoom, having one journal record my initial experience of the class (always recorded immediately after participation), and the other to record my critical and analytical thoughts about the process and experience. ${ }^{19}$ In doing so, I have attempted to draw a theoretical line between an immediate, physical mode of enquiry and a more self-reflexive way of thinking about virtual dance class. As Heewon Chang has suggested, conducting an autoethnography is about using self-observation and self-reflection as data, arguing that performing rigorous autoethnography requires systematic fieldnote-taking or journaling. ${ }^{20}$ My intention was to find out what this change means for the individual and collective experience of dance, which has previously been so bound to specific, specialized sites of dance-space. 
During the Covid lockdown and minimized but prolonged restrictions in Sydney, Australia, I danced at home between two to three times a week, and for the purposes of this paper I will draw from the data I recorded from ballet classes only. In Sydney, the initial lockdown instituted between March $23^{\text {rd }}$ and $29^{\text {th }}$ involved a travel ban, restrictions on gatherings of more than two people, and the closure of eat-in dining, "gyms, indoor sporting venues, cinemas, casinos and entertainment venues." These restrictions were then loosened on May $1{ }^{\text {st }} .21$ The dance classes were conducted on the videoconferencing app Zoom, which has been used extensively by organizations of all sorts over lockdowns to maintain communication between workers when they are staying at home. Its popularity may be explained by its many useful functions, including the ability to mute yourself, turn off your video, screenshare, send text messages, and its innovative display of the current speaker on your screen.

\section{The domestic as feminized space}

The role of the home seems particularly relevant to current discourses because of what "working from home" has come to mean during lockdown. Pre-Covid, scholars like Melissa Gregg were already thinking through our increasing cultural propensity to allow for the bleeding of work and home life, pushed along by our proximity to technologies that promote the possibility of intimacy with and access to our work lives from home and vice versa. ${ }^{22}$ Yet, during lockdown, this proximity has been pressed further, forcing non-essential workers to find ways of working from home for extended periods of time..$^{23}$

As Young argues, for many feminists the concept of home is deeply ambivalent. ${ }^{24}$ The home, as representative of the domestic sphere, has been analyzed as a spatial domain that traps women in the drudgery of housework and relegates them to an existence of supporting the subjectivities and transcendence of others, namely men-while depriving them of their own pursuits and growth. ${ }^{25}$ Yet, as Young points out, such analyses of the home forgo the idea that there might be meaning-making potential in the practice of homemaking. ${ }^{26}$ While I am certainly not claiming that the domestic can only be figured as a prison-like space for women, underlining the ways in which domestic space and the feminine are collapsed is relevant to delving into what it feels like to be confined to home spaces and work within them, and all the connotations this yields with regard to the kinds of work that are positioned as feminine by virtue of their being based within the home.

In light of Covid, wherein the home has become barely distinguishable from the spaces in which we construct ourselves outside of it-for white collar workers in particular, but also for those like dancers, who have physical jobs that take place in specialized spaces that they were barred from - a provocation to take forward is: how does the domestic's construction as feminized space impact its quality as phenomenal space? Drawing this back to my study, there is an interesting layering of notions of women's work at play 
here, relating specifically to ballet as a feminine dance practice. ${ }^{27}$ Ballet is coded as feminine, particularly in public spheres through popular culture; stereotypical signifiers for ballet being "romantic, pink[ness], feminine and attractive." ${ }^{28}$ Further to this, as a historical and culturally dominant institution, ballet can be argued to facilitate ideological hegemony, leaving little room for any challenge to the representation of gender as essentialized and binary. ${ }^{29}$ Despite this strict upholding of the gender binary, male ballet dancers often face ridicule from the outside world for partaking in such a feminized practice; as Angela Pickard notes in her interviews with young male ballet dancers, peers who are not involved in dance tease and bully boys who do ballet, calling them "gay" with derogatory intent. ${ }^{30}$

As such, an investigation into the overlap of the domestic and dance-space seems particularly embroiled in how home spaces and dance practices are gendered. The following analysis reflects this bind, acknowledging both the restrictive and freeing potentials of dancing during lockdown. It is concerned with the ways that the folding of these spaces can challenge how we think about what matters in dance practice and how different it was, and continues to be, to dance in these times. My analysis is divided into three parts, exploring how different dimensions of material domestic space "showed-up" in my practice of attending virtual ballet classes. ${ }^{31}$

\section{I. (A) room to move}

Compared with the extensive, wide-open studio spaces dancers are used to frequenting, attempting to dance in domestic space can be hard. Indeed, for ballet dancers, an array of exercises, namely travelling steps, are made nearly impossible. A theme that stood out from the entirety of my autoethnographic journals was how my limited space impacted my ability to dance "full-out." The notion of dancing full-out is important to understand because it is the apex of what ballet dancers consider dancing to be. Going full-out is dancing with every inch of yourself, using all of your energy, dance-space, and expressive capacity. The modality of dancing in this way-taking up space and using one's own bodily capacity to its greatest extent, is comparable to what many of Merleau-Ponty's critics, including Young, have argued his phenomenology relies upon: a "universal" and "transcendent" experience of being in the world. ${ }^{32}$ Particularly with the confluence of music and dance, as an embodied experience going full-out can speak to the elevated states dancers often reference when they are asked about why they dance, including the pleasurable sensations of bodily liberation, flying, and the rush of adrenalin. ${ }^{33}$

Being enclosed by domestic space and attempting to go full-out, but feeling impeded and restricted by my home-setting, I feel as though an appeal to Young's seminal essay, "Throwing like a Girl," is relevant in two senses: in the way she details how girls restrict the use of their entire bodies in the performance of movement; ${ }^{34}$ and that this results in part due to their lived social experience which places them inside the walls of a home, 
when boys are encouraged to go out "yonder."35 The impact of how the domestic is feminized is felt palpably here, imprinting a closed-offness in the bodily comportment of women who were raised to work in their homes. But this need not be constructed as a decidedly negative experience in reference to dancing indoors, an attentiveness to Young's explication of "feminine comportment" is a helpful way of theorizing movement in limited space, ${ }^{36}$ and, disrupting normative ideas that suggest achieving "flow" and expansiveness in dancing are intrinsic technical goods. ${ }^{37}$

Despite the axiological understanding of dancing full-out as dancing proper, when professional or trainee dancers take their daily class, going full-out is not necessarily required or even encouraged. This is because to get through an hour and a half of nonstop physical activity, plus the rest of the working or school day, you have to pace yourself; and in a way, fine tuning this is one of the hardest things to achieve. Yet, in dance world discourse and dance scholarship, there is still an emphasis on the transcendent ideal of achieving a state of going full-out. ${ }^{38}$ Engaging with the state of resisting that, however, is something that became particularly noticeable when I took class on Zoom, and urged me to consider how, to draw on terms used by phenomenologists, my (historical and habitual) body-schema was in conflict with my (current) bodily "I can." ${ }^{39}$ Since my ballet body history was repeatedly coming-up against trying to practice as it always has, with plenty of space, a dialectical conflict was occurring with my learned manner of dancing and the lack of space that I had to do it in.

For Merleau-Ponty, the body's relationship to the world is intentional, informed by its history, acquired habits and a milieu of other factors, along with human beings' preconscious systems of bodily movements. ${ }^{40} \mathrm{He}$ calls that the "body-schema." ${ }^{41}$ The present body, the "I can" body, ${ }^{42}$ inhabits space in a way that is dictated by the bodyschema, and depending on what kinds of space it is inhabiting, the body-schema can show-up for, or conflict with, the material world in different ways. Consider the feeling of having spent some time on a boat and then stepping back on land. The rocking sensation, having sea legs, is a result of the body-schema clashing with the body's habitation of space at that moment.

I have never been a good turner, so the sense of there being a lack of space felt especially visceral during turning exercises. Even in dance studios I become more aware of my surroundings when turning, for instance if someone is dancing close to me. When I took ballet classes on Zoom, it was often a toss-up between having room to move and having access to a hard floor. For pirouettes, a hard floor is fairly important, but as I mentioned, space is key for me to feel confident about turning. When I chose to dance on a hard floor, this meant being in a strange room that was connected to, but was not quite, the kitchen. In this almost-kitchen room I was acutely aware of the surfaces that were jutting out at me where I danced. This is where all my appliances live, and as I turned, trying to focus on a spot, I could see them blur around me in a disorientating 
way. Despite being a bad turner, I know that tightening up is not helpful, but doing so was my ingrained bodily response to trying to move in a space crowded with impeding obstacles. It was evidence of my dancer's body-schema confronting its newfound domestic habitat - as such, I would flinch and snatch myself away from intrusions like the corner of a bench or my bathroom door. Any claim I had to fine-tuned proprioception felt decidedly diminished, having to account not just for the positioning of my own body but for the many material bodies that enveloped me.

Yet, as time went on and I continued to take class, my turns in the almost-kitchen room improved. I realized that going full-out here was not only impossible given the spatial restrictions, but trying to do so was also throwing me off. Engaging with that state of embodied resistance, of not quite giving it everything, but instead directing energy in controlled and specific directions, was helpful. I would turn with as little force as I could and focus on the sensations of my supporting foot on the floor, turning into it like a screw, my working leg turning out from the heel of that foot and my knee pressing backwards. Mitigating my momentum came slowly, not just because I was learning to manage my dancing body in a reduced space, but also because I started conceiving of my dancing as part of the materiality, rather than a separate entity bouncing around in it. Conceiving of my dancing in the domestic as being part of a material landscape was like imagining a change in my proprioception, inching it out to encompass the space I danced in.

Of course, the meeting of bodies can end in an opposite way causing significant ruptures and collision. In his ontology of flesh, Merleau-Ponty considers how we experience the world through touch, which is in essence the meeting of different bodies; he used the term "chiasm" to evoke the "crisscrossing ... of the touching and the tangible." ${ }^{\prime 3}$ Merleau-Ponty contends that the ways in which bodies and beings experience and perform touch is in fact the way that they incorporate themselves into, and come to know of, the world, which is important because of the emphasis it places on the site and boundary of touch, the "chiasm." 44 In coming to know of and act within the world like this, there are undoubtedly moments of collision, where the meeting of bodies causes rupture, as there always are in learning experiences. Indeed, in April 2020, when lockdowns were fairly widespread globally, Instagram videos of dancers accidentally clashing with their surroundings while immersed in movement were popping up frequently: one dancer touches a freshly painted wall with the tip of her pointe shoe in the middle of a promenade, and one has an ongoing battle with the ceiling fan in her living room that she clips with her fingers and feet.

\section{Carpet}

My home's extensive carpeting caused another clashing of body-schema with domestic world, which was particularly pronounced in my attempt to execute fundamental ballet steps such as tendus. A tendu involves the dancer's supporting leg remaining still and 
straight underneath them while the working leg extends out and the foot almost comes off the floor-heel first, then arch, then metatarsal until just the toes are connected to the floor and the foot is fully stretched in a pointed position. Then everything happens in reverse and the working foot joins the supporting one in a closed fifth or first position. Tendus are performed early on in class at the barre to warm up the feet and legs, but they are also a fundamental part of almost all other ballet steps, much like the plié. I recall dance teachers telling us to "lick the floor with your feet," and to "push the floor away from you" as we practiced tendus. Such directions are part of a pedagogical language allowing teachers to convey embodied sensation, to let their students know what something should feel like if they are doing it correctly, promoting thinking with and through the body. Having done tendus for upwards of twenty years, I enjoy that sensation of my feet pressing against the floor to form a pointed position. I love to feel the articulation of the muscles and bones working in succession to resist the destination, prolong the movement, but arrive at the end position nonetheless.

Doing a tendu on carpeted floor is unsatisfying. Whether you are barefoot, wearing socks or ballet shoes, nothing feels right. Dancing on carpet during Zoom classes left me with burns on my feet and a profound sense of frustration. Mainly because carpets create friction-so tendus, pirouettes, and chassés are all made much more difficultdoing anything that requires your body to be in contact with the floor while moving is hard. This experience of dancing in domestic space was consistently annoying. Over the four months I journaled when dancing on carpeted floor, I recorded feeling "pent-up," "frustrated," and "generally unsatisfied" with class. In bodily terms I felt as though I was "sticking," "jarring," and "tripping over myself." My underwhelming experiences of ballet-on-carpet appear to have been felt by professional dancers too, who sometimes have the added difficulty of attempting to dance on carpet en pointe. One female dancer posted a video on her Instagram of a montage of her at-home exercises en pointe, on carpet, accompanied by a caption that reads "Pointe shoes on carpet," followed by an "emoji" icon displaying gritted teeth. In fact, I remember the sensation of going en pointe on carpeted floor from when I used to visit my grandparents' house to take audition photos. It is a spongy sensation, and feels as though the flat end of your pointe shoe is rounded, making it harder for your ankles to stabilize.

It does not escape notice that carpets are designed to maximize comfort and retain warmth in domestic contexts. As Young contends in her essay "House and Home: *":

Home is the space where I keep and use the material belongings of my life. [...] The home is not simply the things, however, but their arrangement in space in a way that supports the body habits and routines of those who dwell there. The arrangement of furniture in space provides pathways for habits - the reading lamp placed just here, the television just here, the particular spices on the rack placed just so in relation to this person's taste and cooking habits. ${ }^{45}$ 
What Young suggests in this passage is that the material practice of homemaking bears witness to the sediment of our lives, acting as a physical reflection of lived experience. ${ }^{46}$ Her intention is to grapple with the potential for meaning making in the feminized practice of homemaking, but mine is to consider what the impact of colliding with this sediment might be, and how doing so can displace the elite status of the studio. Because carpets are made to caress our bare feet in the morning after climbing out of bed - not to allow for a tendus, jumps, and multiple turns - when these challenges to dance practice brought by the sediments of our domestic lives are confronted, and navigated (albeit imperfectly), there is an opportunity to debunk the almost mythologized pre-eminence of studio space.

Through this account of carpeted floor told through tendus, I have been able to examine the ways that the domestic conflicts with and rubs-up against my ballet body-schema. In a phenomenological sense, everything about my classical ballet training makes me resistant to the way dancing on carpet feels, because so many of the pleasurable sensations of body-meets-world are missing: the pressure of my foot moving against the smooth floor in a tendu; the reverberating rebound of jumping on sprung studio floor; and the satisfying squeak of my shoe on tarkett as I pirouette. Also due to the failure of my body to "cope," as Dreyfus says, with these new circumstances ${ }^{47}$ Dreyfus's phenomenological sketch of "skillful coping" works to fill a gap that Merleau-Ponty leaves in his discussion of skill, relating to the early stages of skill acquisition. ${ }^{48}$ In regard to my body's failure to cope, then, I am positioning myself as an amateur in the specific context of dancing on carpet, which can only be altered by repeating the activity so that my body develops sensitivities to the texture of the carpet, developing skill to manage in the situation.

While I am not claiming that most dancers are not wishing for a return to pre-Covid normalcy, where they can enjoy specialized dance spaces, the ways in which dancers have managed, and excelled, at carving out dance-space in domestic settings is a gesture toward the notion that dance can happen in non-dance spaces productively. As Young notes, because our homes as a reflection of our lives suggest some things-that these spaces mirror the body's need to rest and recuperate in ${ }^{49}$ with regard to carpeted rooms more specifically-does not mean there is no scope for repurposing them and appropriating them for exactly the opposite. The intent of displacing the elite status of the studio is to increase accessibility to an artform that constructs a certain gravitas around itself and its privileged spaces. It is also not surprising that an investigation into layered notions of, and assumptions about, feminized work and the spaces this occurs in, has provided insight into how it may be possible and productive to dispute the primacy of specialized work spaces such as a dance studios, where the assumed "real," transcendent business happens. 


\section{Screen}

The definitively "new" aspect brought into dance training by Zoom classes is the presence of the screen as the point from which dancers are directed. Resultantly, the screen takes on a role within the assemblage as an actor. It is a human-tech hybrid, as the physical screen works like a prosthesis for the dance teacher on the other end, who is then able to communicate with their students or dance company members to facilitate training. ${ }^{50}$ When one partakes in these virtual classes, the screen can feel like an odd presence out of which emanates the voice of whoever is teaching you that day. Although it is possible to see the teacher, due to the nature of dancing you are forced to stand back, away from the screen, so having a voice direct you from an inanimate object feels strangely disembodied. Thinking of the screen as an actor was important for me in three senses: (1) it allowed me to consider the ways in which I was orienting myself towards the screen, (2) it allowed me to consider the ways in which I was curating my space for the screen, and (3) it allowed me to imagine the phenomenal space on the "other side" of the screen.

In terms of orienting myself, I would feel most comfortable attending classes when I had spent some time before ensuring that I would appear well on screen. Elements of this included having my whole body visible and ensuring the angle from which I appeared was not unflattering. This also tied into my broader curation of the domestic space around me that would appear on screen. Generally, I developed a habit of simply rearranging any mess so it sat just behind my screen. I also tried to ensure that the setting I appeared from was not too distracting for the teacher viewing it. Corroborating this, I found that many other participants appeared to replicate this kind of aesthetic curation by tuning in from white-walled spaces with minimal decoration. The organization of these two elements, the way that my background and I appeared on screen, was an attempt to organize the phenomenal space on "my side," and how I would appear primarily on my teacher's screen but also on that of other participants. Although this may appear to have a narcissistic grounding, over the lockdown period I found it was increasingly important to me as I invested more of myself into my screen time. Much as going out to take class at a dance studio in situ feels like an expression of my identity and the development of my own particular subjecthood, as we were restricted from moving and being freely in the outside world, more of this subjectbuilding was tied entirely to my expression of myself through Zoom.

In some ways, the screen took on the role of dance studio mirror, much like I would orient myself towards the screen during Zoom classes, in a dance studio I would use the mirror to tweak my appearance and adjust my body. Without wanting to make assumptions regarding what Young might think about the mirror's role in ballet, it might be fair to predict that she would be at least suspicious of it, particularly for its impact on women dancers. As she puts forward in "Throwing like a Girl," by virtue of their positioning as object as well as subject, women are socially conditioned into 
internalizing their objectification, which causes them to watch themselves and police their own bodies, and consequentially has the impact of inhibiting their movements. ${ }^{51}$ As many scholars, including Jill Green, Anna Aalten, and Angela Pickard, ${ }^{52}$ have claimed in a multitude of ways, the mirror in dance studios can represent this internalized external gaze, and suggests that this gaze is inherently pathologizing. Although I do not wholly agree with this critique, since the mirror always felt like more of a tool than anything else for me, the absence of the mirror might be productive for dancers in variety of ways.

Due to the nature of most personal device screens, such as laptops, being relatively small and their associated cameras providing less than high-definition pictures, combined with the fact that when you are partaking in a Zoom dance class you need to be relatively distanced from the screen to execute movements, the screen does not make a very good substitute for a mirror. As such, rather than considering the screen as a replacement mirror, it is more interesting and fruitful to think about the screen as a virtual embodiment of the teacher, who establishes a vocal, even physical presence in whatever room you are dancing in. Without the mirror, but with the guidance of the screen/teacher, it is arguably easier to focus on the correct sensations, of bodily placement for example, and learn through those, than by self-correcting through the mirror, which can result in those sensations coming secondarily to visual cues of proper alignment. I have a tendency to "get lost in the mirror," so dancing without one was a liberatory experience. I was able to focus on engaging with any corrections and guidance teachers offered and simply enjoy dancing without the temptation of glimpsing toward my reflexive tool.

Any "personal" experience is, of course, formed within larger social contexts. As I noted earlier, the potentially equalising effect of the workplace, in this case the dance studio, is lost, and felt quite intensely when partaking in virtual activities. Being able to afford an expansive room to dance in at home is quite a luxury, and other elements of material space are pronounced too, such as the access to specialized objects participants had in their homes. Some professional dancers had squares of tarkett or linoleum flooring while others did not, and struggled along on carpet or slippery wood. But even in the virtual classes that I did-which were generally not of a professional level because of the implications of offering advanced classes that anyone could sign up for and the possibility of injury occurring-participants had objects like ballet barres. Having a purpose-made ballet barre is an extreme advantage, as opposed to grabbing a kitchen countertop, chair, or door handle-all of which I tried and all of which resulted in my hand cramping or having an awkward support for the first half of class. The finding here is that although bodily pursuits like ballet present themselves as inherently favoring those with natural elite potential and inherent talent, the same material inequalities exist for dancers whether they are working at home or in a studio space. Spending copious amounts of time in the studio, however, gives the appearance of a level playing field, without accounting for the advantages or disadvantages of home space. 
Yet despite this stratifying effect, the Zoom space also produces experiences of some sort of communality, if not commonality. By the "other side" of phenomenal space, I imagine the screen as its own virtual two-dimensional plane, but also how others participating in Zoom classes might perceive me as a part of their screen. Although it is hard to watch other participants during a Zoom class, if you do flick to tile mode where you can see multiple squares on your screen, a patchwork fabric of dancers manifests itself. It is as though each dancer has their own box; sometimes they mirror one another, seemingly dancing together, creating patterns organized by whatever algorithm Zoom uses to order the boxes on participants' screens. The planes of space, from one's own screen, to an imagined intermediary virtual plane, to somebody else's screen, suggest an inhabitation of domestic space in new kaleidoscopic ways. Since it is possible to be both in your own living room and simultaneously feature in a Zoom square on stranger's screen, who is also inhabiting their own domestic setting, we can destabilize the construction of "I" as a singular and whole identity, understanding our virtual iterations as multiples of ourselves. Indeed, in the phenomenological sense, I certainly felt as though my own box on the screens of others had agential capacities. For example, I was unsure if I would unwittingly dance in the wrong direction and it would be apparent on other participants' screens but not my own, as the automatic "mirror" function on Zoom applies to your reflection of yourself, but not to your box on the screens of others.

This also contributes to the notion of a participant imaginary. There are moments, always at the end of class, when the dancing is over and everyone comes forward towards their camera, and thanks the teacher, and sees who they have been dancing with. It is often an emotional moment, particularly when there are a significant number of dancers - the largest class I danced with featured 103 participants. As people are "unmuted" at the end of the session, faces flash up on your screen saying "thank you" to the teacher, all looking tired and flushed and grateful. As this happens, you get just a brief idea of that person's context, and sometimes you can tell a little about where that person is in the world; whether it is day or nighttime, the interior design of the room, and occasionally people would place a small flag to indicate where they were from in their Zoom name (which appears with your box at all times). Getting an idea of the breadth of places people were tuning in from to attend class made me feel such a strong sense of a global community. And to think that across the world a seemingly random group of people were all doing the same dance in their living rooms, kitchens, bedrooms and garages, at the same time, felt like a genuine expression of multiplicity but also communality and connection, echoing into our homes through our screens.

\section{Conclusion}

The aim of this critical phenomenology of taking virtual ballet class during lockdown, has been to investigate the folding over of dance-space onto the domestic, and particularly what it feels like to dance in the time of Covid. In my analysis of the standout elements of my virtual dance experience-the lack of room to move, the carpet, and 
the screen-I have attempted to unpack the ways that my classically trained ballet body-schema collided with and adapted to its mapping onto domestic space. On a personal level it was a frustrating and chaotic, but altogether valuable experience.

This study has helped to unearth, in conjunction with an appeal to the ways that Young analyzes and interprets the domestic, how the domestic as dance-space is gendered, how it might be possible to rethink the specificity of domestic spaces to make them work for us, and how we might shift our understanding of dance as a placed-based practice. In a small way, as I do not believe my experiences can be representative of anyone else's, it has shown that through the moments of conflict and rupture, there can be technical, creative and emotional gains. It has also made clearer the extent to which the home as a site of privilege can impact on a dancer's training, and in doing suggests we should continue to challenge the ways that classical ballet as an institution constructs itself as a pure meritocracy of natural talent.

From the perspective of a minutely detailed, under-the-surface scale, this autoethnographic exercise has illustrated the possibilities for remaking the home as space that can facilitate physical training and artistry, while recognizing the multitude of difficulties that can accompany this with regard to affordances of material space and the labor time of those who are confined to their home spaces. I have suggested there are also benefits to questioning the primacy of the dance studio as the only place in which "real" dance work can happen. I am hopeful for myself, that in returning to the studio, I will retain the sensitivity I developed to my domestic space in taking up future dance spaces, and that the dance world as a whole will not forget its tenacity and adaptability. There is something magical about performing a dance you know is happening across the world, in many homes, in many rooms, by many bodies; distant and separate, but in time with your own.

\section{Biography}

Francesca Ferrer-Best is a PhD candidate with the Department of Gender and Cultural Studies at the University of Sydney. She commenced her vocational ballet training in London before deciding to pursue an undergraduate degree in Modern History and Politics at the University of Manchester. Her broad academic interests include phenomenology, movement cultures, embodiment and drinking. Francesca's doctoral research is motived by academic feminism's tendency toward pathologizing ballet dancers, and aims to unearth and communicate dancers' experiences in an in-depth, embodied analysis of how ballet dancers interface with the world. She employs phenomenological, sense-based thinking to get at the different scales and situated nature of dance experience. Outside university, she is happily involved in the 
independent dance-making community in Sydney. She works, writes, and dances from the unceded, stolen land of the Gadigal people of the Eora Nation.

Email: ffer9131@uni.sydney.edu.au

Notes

${ }^{1}$ Shitagi, The Ballerina Project.

2 Young, On Female Body Experience, 123.

${ }^{3}$ Merleau-Ponty, Phenomenology of Perception.

${ }^{4}$ Miller, Playing Along, 7.

${ }^{5}$ Boellstorff, Coming of Age in Second Life, 5.

${ }^{6}$ Ibid. 19.

${ }^{7}$ Miller, 8.

${ }^{8}$ Toffoletti, The Conversation.

${ }^{9}$ Ibid.

${ }^{10}$ Harlig, Social Texts, Social Audiences, Social Worlds, 17.

${ }^{11}$ lbid. 17-18.

${ }^{12}$ Ibid. 19.

${ }^{13}$ Bench, Perpetual Motion, 119.

${ }^{14}$ Ibid.

${ }^{15}$ lbid. 156.

${ }^{16}$ Collins, "Working Out the Contradictions," 85.

${ }^{17}$ Ibid.

${ }^{18}$ Ibid.

${ }^{19}$ Chang, Autoethnography as Method, 95.

${ }^{20} \mathrm{lbid} .89$. 
${ }^{21}$ Wahlquist, "Australia's Coronavirus lockdown."

${ }^{22}$ Gregg, Work's Intimacy, 2.

${ }^{23}$ Non-essential workers are those who are not essential to the basic functioning of society in the midst of a pandemic, some essential workers included: doctors and nurses, supermarket workers, and transport workers.

${ }^{24}$ Young, 124.

${ }^{25} \mathrm{Ibid}$. 124. Young is grappling with a formidable feminist canon here, citing Simone de Beauvoir and Luce Irigaray, and the argument she makes can be taken further now, which is that de Beauvoir was thinking about the home as a bourgeois "commodified home," and Irigaray was conceiving of home as the "maternal home"- and that these critiques are embedded in their own distinct contexts and temporalities. De Beauvoir's criticism was of consumerism in the 1950s, and Irigaray's was strongly influenced by psychoanalysis in the mid-1970s and early 80 s. Though surely apt and relevant, they no longer exactly, or only, apply. Indeed, they only ever directly applied to some middle-class women.

${ }^{26}$ Ibid. 147.

${ }^{27}$ It should be noted that I am relying on gender essentialising terms to appeal to what is socially constructed as a settled binary of gendered performance.

${ }^{28}$ Pickard, Ballet Body Narratives, 58.

${ }^{29}$ Novack, "Ballet, Gender and Cultural Power," 42.

${ }^{30}$ Pickard, 71.

${ }^{31}$ Dreyfus and Wrathall, Skillful Coping, 235. Hubert Dreyfus was an American philosopher who was strongly influenced by Merleau-Ponty's work; using it to challenge early developments of artificial intelligence based on certain ontological and epistemological assumptions. I have relied on Dreyfus' expert application of Merleau-Pontian theory to enrich my use of his thinking.

${ }^{32}$ Young, 35-36.

${ }^{33}$ Paskevska, "On Zen, Flow, and Being in the Dance," 102; Wellard, Pickard and Bailey, "'A shock of electricity," 79; Pickard, 125.

${ }^{34}$ Young, 28.

${ }^{35}$ Ibid. 39-41.

${ }^{36}$ Ibid. 32. 
${ }^{37}$ Paskevska, 103.

${ }^{38}$ Ibid.; Pickard, 145-46.

${ }^{39}$ Merleau-Ponty, Phenomenology of Perception, 131.

${ }^{40}$ Ibid.

${ }^{41}$ Ibid.

${ }^{42}$ Ibid.

${ }^{43}$ Merleau-Ponty, The Visible and the Invisible, 133.

${ }^{44}$ Ibid.

${ }^{45}$ Young, 139.

${ }^{46}$ Ibid. 140.

${ }^{47}$ Dreyfus and Wrathall, 232.

${ }^{48}$ Ibid. 234.

${ }^{49}$ Young, 139-40.

${ }^{50}$ Haraway, "Situated Knowledges," 588-89.

51 Young, 44-45.

${ }^{52}$ See for example, Green, "Foucault and the Training of Docile Bodies"; Aalten, "'The Moment When it All Comes Together'"; Pickard, "Ballet Body Belief."

\section{References}

Aalten, Anna. "The Moment When it All Comes Together': Embodied Experiences in Ballet," European Journal of Women's Studies 11.3 (2004): 263-276. https://doi.org/10.1177/1350506804044462

Bench, Harmony. Perpetual Motion: Dance, Digital Cultures, and the Common. Minneapolis: University of Minnesota 2020. https://doi.org/10.5749/9781452962627

Boellstorff, Tom. Coming of Age in Second Life: An Anthropologist Explores the Virtually Human. Princeton: Princeton University Press, 2008. 
Chang, Heewon. Autoethnography as Method. New York:Taylor and Francis Group, 2008. Collins, Leslea Haravon. "Working Out the Contradictions: Feminism and Aerobics", Journal of Sport and Social Issues 26.1 (2002): 85-109. https://doi.org/10.1177/0193723502261006

Dreyfus, Hubert L. and Mark A. Wrathall. Skillful Coping: Essays on the phenomenology of everyday perception and action. Oxford: Oxford University Press, 2014. https://doi.org/10.1093/acprof:oso/9780199654703.001.0001

Gregg, Melissa. Work's Intimacy. Cambridge: Polity Press, 2011.

Green, Jill. "Foucault and the Training of Docile Bodies in Dance Education," Arts and Learning 19.1(2002): 99-126.

Haraway, Donna. "Situated Knowledges: The Science Question in Feminism and the Privilege of Partial Perspective." Feminist Studies 14.3 (1988): 575-599. https://doi.org/10.2307/3178066

Harlig, Alexandra. Social Texts, Social Audiences, Social Worlds: The Circulation of Popular Dance on YouTube. PhD Dissertation. Ohio State University, 2019.

Merleau-Ponty, Maurice. The Visible and the Invisible. Evanston: Northwestern Univeristy Press, 1968.

---. Phenomenology of Perception. Taylor and Francis Group, 2012. Originally published in 1945. https://doi.org/10.4324/9780203720714

Miller, Kiri. Playing Along: Digital Games, YouTube, and Virtual Performance. Oxford: Oxford University Press, 2011. https://doi.org/10.1093/acprof:oso/ 9780199753451.001.0001

Novack, Cynthia. "Ballet, Gender and Cultural Power". Dance, Gender, Culture. Ed. H. Thomas. London: Palgrave Macmillan. 34-48. https://doi.org/10.1007/978-1-349$23842-2$

Paskevska, Anna. "On Zen, Flow, and Being in the Dance." Journal of Dance Education 1.3 (2001): 102-105. https://doi.org/10.1080/15290824.2001.10387187

Parrish, Mila. "Toward transformation: Digital tools for online dance pedagogy." Arts Education Policy Review 117.3 (2016): 168-182. https://doi.org/10.1080/ 10632913.2016.1187974

Pickard, Angela. "Ballet Body Belief: Perceptions of an Ideal Ballet Body from Young Ballet Dancers," Research in Dance Education 14.1 (2013): 3-19. https://doi.org/10.1080/14647893.2012.712106 
---. Ballet Body Narratives: Pain, Pleasure and Perfection in Embodied Identity, Oxford: Peter Lang, 2015. https://doi.org/10.3726/978-3-0353-0717-7

Shitagi, Dane. "Francesca Hayward in London." Ballerina Project. Instagram. Posted Mar. 32020.

Toffoletti, Kim, Adele Pavlidis, Holly Thorpe and Rebecca Olive. "Working out at home works for women-so well they might not go back to gyms." The Conversation. Posted Mar. 27 2020. https://theconversation.com/working-out-at-home-works-for-womenso-well-they-might-not-go-back-to-gyms-138111

Wahlquist, Calla. "Australia's Coronavirus lockdown: the first 50 days." The Guardian. Posted May 2 2020. https://www.theguardian.com/world/2020/may/02/australiascoronavirus-lockdown-the-first-50-days

Wellard, lan, Angela Pickard and Richard Bailey. "'A shock of electricity just sort of goes through my body': Physical activity and embodied reflexive practices in young female ballet dancers." Gender and Education 19.1 (2007): 29-91. https://doi.org/10.1080/09540250601087793

Young, Iris Marion. On Female Body Experience: "Throwing Like a Girl" and Other Essays. Oxford: Oxford University Press, 2005. https://doi.org/10.1093/0195161920.001.0001 